\title{
The Risk Identification and Prevention Strategies in State-owned
}

\section{Enterprise Transnational Merger}

\author{
Weizhu Wang ${ }^{1, a}$ \\ ${ }^{1}$ School of management, Shanghai Univer, Shanghai, China, 200444 \\ a email:
}

Keywords: State-owned Enterprise, Transnational Merger, Risk Identification, Prevention Strategy

\begin{abstract}
With the continuous expansion of China's foreign direct investment scale, the pace of cross-border merger and acquisition of state-owned enterprises is also greatly accelerated, at the same time, many risks - politic, law and value merger and acquisition risk appear one after another, which restricts the development of transnational mergers and acquisitions of state-owned enterprises to a certain extent. Based on the author's work experience, this paper firstly identifies the risks in the transnational merger and acquisition of state-owned enterprise, then puts forward the system of risk prevention of state-owned enterprise cross-border mergers and acquisitions.
\end{abstract}

\section{Introduction}

With the development of the integration of economic globalization, transnational investment has become the most important way of international direct investment, and the transnational mergers and acquisitions have a huge impact on the world economy. However, due to the information asymmetry, in cross-border mergers and acquisitions, enterprises may face a variety of risks. Therefore, it is of practical significance to study the risk identification and prevention strategy of the transnational merger and acquisition of state-owned enterprises.

\section{The Risk analysis of Transnational Merger and Acquisition of State-owned Enterprises}

Politic risk. Politic risk means the possibility of economic losses of the merger and acquisition enterprises caused by the changes in the political relations of the two countries. For state-owned enterprises, the failure rate of overseas merger and acquisition is higher than that of private enterprises, and the political factors is the main reason. Because of the different political system and economic system in various countries, in the cross-border mergers and acquisitions, China enterprises often encounter all sorts of obstacles and suspicion, especially state-owned enterprises, the problem of ownership is often misunderstood the purpose of mergers and acquisitions. Host country and target companies worry if the enterprises are acquired, the domestic resources will be monopolized, the economy will be damaged, and even will endanger national security. This kind of political hostility makes the state-owned enterprise's overseas merger and acquisition be full of difficulties. The government may even intervene in the acquisition program directly using the law or administrative means, causing the failure of the project or to make the merger and acquisition enterprises suffered huge losses. In 2005, CNOOC’s biding for Unocal, CNOOC planed to carry out the acquisition of $\$ 18$ billion 500 million, which is 1 billion 500 million dollars higher than Chevron Co. However, the United States Congress members signed a letter, and they made a lot of 
excuses, such as energy threat, national security and master core deep sea technology, so that the acquisition failed. At present, the political risk is not only the most deep-seated reasons that restrict the cross-border mergers and acquisitions of state-owned enterprises, but also the most unpredictable risk.

Legal risk. Legal risk means the losses brought by the unexpected control and sanctions because they do not understand the relevant laws of the host country after the success of mergers and acquisitions. That is to say, from the beginning of the review of the foreign capital merger and acquisition of host country, the legal risk of cross-border merger and acquisition has been running through the whole process of the management of the target enterprise after the success of merger and acquisition. Many countries will conduct legislative norms on mergers and acquisitions, including anti trust law, securities law, company law, etc. If it violates these laws in the process of mergers and acquisitions, it will inevitably leads to failure. In merger and acquisition, merger and acquisition enterprises will face a lot of creditors, and only got the approval of the creditors, the target corp can sell assets. merger and acquisition company not only needs to inherit the assets of the target corp, but also need to bear the liability and legal liability of the target corp. In the process of successful mergers and acquisitions, enterprises still face a certain degree of legal risk, for example, it may violate the host country's anti-monopoly law for the maintenance of market competition and the interests of consumers, contract risks in the merger and acquisition contract may also bring huge losses to the enterprise.

Value risk. Value risk refers to the problem of information asymmetry in the process of merger and acquisition. If the merger and acquisition enterprises can not fully understand the information of the target enterprise, it may estimate the value of the merger and acquisition enterprises with a high price. Merger and acquisition is the main way for multi-National corporation to enter new markets as soon as possible and to achieve rapid expansion. In order to maximize the benefits of state-owned enterprises through mergers and acquisitions, it is required to determine the value of merger and acquisition price in the merger or acquisition of foreign enterprises in line with the actual value of the target enterprise. But in the process of cross-border merger and acquisition, the problem of information asymmetry is widespread.Target companies are always more aware of their own actual situation, problems and development prospects than the merger and acquisition enterprises. There is a certain degree of difficulty for merger and acquisition enterprises to obtain relevant information, most information comes from corporate financial statements and annual reports, and the authenticity and objectivity of the information is limited, there are some intangible assets such as management level, brand value, business reputation, they are difficult to be reflected in the financial statements. In the process of mergers and acquisitions, our country does not do enough to guard against these risks, lacking of long-term tracking for foreign enterprises, does not make a thorough analysis and understanding for the target enterprise information, which will lead to an increase in the cost of mergers and acquisitions, and affecting the actual impact of mergers and acquisitions.

Integration risk. Integration risk means the risk of failure of merger and acquisition brought by the reorganization of tangible resources and the integration of intangible resources after merger and acquisition activity is completed. The re-allocation of the resources of the two parties is a very important content of the enterprise after merger and acquisition, and it is also the key to determine the success or failure of merger and acquisition. Because of the difference of enterprise culture, the organization, the management concept, it will cause the difficulty and failure of integration. When SAIC mergers Ssangyong Motor, it aroused strong opposition from the Korean union due to the attribution of the brand, property rights, business restructuring and other aspects. Because 
Ssangyong did not achieve complete integration and transformation, Suffered a heavy blow in the economic crisis of 2008, and it tries to reduce the burden of layoffs, causing the industry will once again dissatisfied, in January 9, 2009, SAIC filed for bankruptcy protection in Seoul, South Korea, and merger and acquisition failed in the end.

\section{The System Design of the Risk Prevention of Transnational Merger and Acquisition for the State-owned Enterprises}

Configuring resources based on the international market, strengthening coordination and integration, reducing the production cost of state-owned enterprise merger and acquisition. After merger and acquisition, enterprises should pay more attention to the complementarity and correlation of the resources of the two parties, make full use of international market resources integration, reduce the cost of management, raw materials and production and other aspects. Generally speaking, transnational enterprises in the process of merger and acquisition integration includes strategic integration, resource integration, management integration and culture integration of the enterprise. Enterprise development strategy provides the enterprise mission and basic objectives, the concept and purpose of the enterprise, it is the basis for the enterprise to make the development plan and the implementation of the development strategy. After cross border mergers and acquisitions, enterprises should analyze their own internal and external environment changes, study on the existing strategies of merger and acquisition enterprises for the corresponding integration and reconstruction, make it adapt to the overall strategic requirements of the enterprise, to avoid the two sides of the strategic mismatch caused by the new business direction. Resource integration includes material resources and human resources. Material resources should consider both tangible and intangible assets, tangible assets are business operations and the material basis for the development; Intangible resources includes brands, technology, but also a direct impact on the ability of a company's market competition. Another important resource is talent, after the merger and acquisition, it is a critical factor for the state-owned enterprises whether they can keep the management and technical personnel. In the process of human integration, it should recognize the differences in human resources between the two sides, strengthen communication to fully understand the staff will, properly resolve the contradictions. According to the specific circumstances, management integration should investigate and understand the business objectives of the original management system operation mechanism, advantages and disadvantages, comb the merger on both sides of the management organization structure, integrate management system, thereby increasing the operational efficiency of enterprises. Cultural integration is the key and difficult points in the integration of merger and acquisition. Different enterprises have their own corporate culture, especially in cross-border mergers and acquisitions, the cultural differences coming from different countries performs prominently.

Actively improve the state-owned enterprise system, reduce the transaction costs of state-owned enterprises mergers and acquisitions. The direction of the reform of state-owned enterprises is to establish a modern enterprise system. To speed up the improvement of the modern system of state-owned enterprises, improve the quality of state-owned enterprises, and enhance the vitality of the state economy. One reason for the failure of state - owned enterprises in cross-border merger and acquisition is failing to do a good job for investigation and planning before the merger. It is a critical step to assess the value of the target enterprise scientifically and reasonably and to make the right decision. In the process of evaluation, first of all, it should ensure that whether the information on assets, liabilities and goodwill for target enterprise are full, at the same time, the merger and acquisition can also obtain relevant information from the well-known accounting firms 
in the host country, to understand the history, current situation, problems, reasons and the development potential of the target enterprises. To obtain the target enterprise's sales channel and core technology is one of the main motivations for the state-owned enterprises to carry out cross-border merger and acquisition, in order to ensure the access to these values, it is necessary to have a deep understanding of the target enterprise in this regard. After obtaining the information and data, the merger and acquisition enterprises should not be too optimistic, it should choose reasonable evaluation methods, scientific evaluation model to carry on the objective and detailed analysis, accurately grasp the target enterprise's current value and potential value, so as to make a correct decision on the price of merger and acquisition. In addition, because the understanding of the two sides of the merger is different to the value of the enterprise, in the course of negotiation, there will be a bargaining process, which requires China's enterprises should fully consider the details of the negotiations to analyze the conditions of the negotiation concessions, and forecast the problems that may arise.

Transform government function, reduce the production cost and transaction cost of state-owned enterprise merger and acquisition. Deepening the reform of administrative system, innovating the administrative management, enhancing the credibility and the executive power of the government are effective means to reduce the cost of mergers and acquisitions. It requires the government to establish overseas investment insurance system, and establish the official nature of overseas investment insurance agencies, so that it can help Chinese enterprises to disperse and prevent risks in mergers and acquisitions. The establishment of the official nature of the overseas investment insurance agencies can help Chinese enterprises to spread and prevent risks in mergers and acquisitions. On the other hand, the government should also establish an inspection system for foreign investment in state-owned enterprises, supervising and standardizing the behavior of enterprises overseas mergers and acquisitions, to check the effect of mergers and acquisitions. From the policy to encourage and support the state-owned enterprises overseas mergers and acquisitions, simplifying approval procedures, shortening the approval time, and establishing a simple and efficient investment management approval procedure. In order to prevent the financial risk of merger and acquisition, through the financial audit system, the government can strengthen the supervision and examination of the financial situation of enterprises. Through the improvement of the foreign exchange management system, the government can timely understand the intention of mergers and acquisitions of enterprises, and review the investment direction of enterprises.

\section{Conclusion}

Cross border mergers and acquisitions of state-owned enterprises can bring considerable benefits, but it also faces many multiple risks. In order to promote the further development of cross-border merger and acquisition, the government should play an active role in guiding and regulating to decentralize the investment risk state-owned enterprise transnational merger. For state-owned enterprises, it needs to deepen reform, improve the modern enterprise system, comply with the laws of the market economy, in accordance with the rules of the international business organization and management. Transnational mergers and acquisitions of state-owned enterprises make our country's enterprises step into the international market, which can implement the "going out" strategy of the state-owned enterprises.

\section{Reference}

[1] Li Shan. Study on risk and Countermeasure of transnational merger and acquisition of 
state-owned energy enterprises [D]. Southwestern University of Finance and Economics, 2014.

[2] Tang Jijun, Enron. The system of risk prevention of transnational merger and acquisition of state owned enterprises [J]. economic system reform, 2015,03:118-123.

[3] Sun Xiping. Risk analysis and prevention of transnational merger and acquisition of state owned enterprises [J]. Journal of Finance and accounting, 2010,30:16-18.

[4] Zheng Shijin. Study on the risk of transnational merger and acquisition of Chinese enterprises [D]. Zhejiang University, 2007

[5] Chang Wenfang. Study on financial risk management of Chinese enterprises cross border mergers and acquisitions [D]. Lanzhou University of Technology, 2009

上海市徐汇区吴中东路 555 号 8 楼 804 室 徐禕澍收， 13621656554 